\title{
1 Network Analysis for Species Management in Rivers Networks: 2 Application to the Loire River
}

3

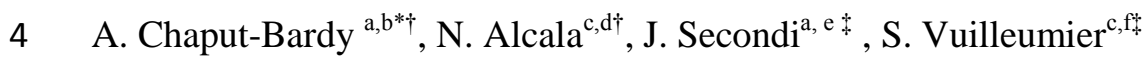

5 a GECCO, Groupe Ecologie et Conservation des Vertébrés, Université d'Angers, UFR Sciences, 2

6 Boulevard Lavoisier, F-49045 Angers cedex 1, France

$7 \quad$ b La Maison du Lac de Grand-Lieu, rue du Lac, F-44830 Bouaye, France.

$8 \quad{ }^{c}$ Department of Ecology and Evolution, University of Lausanne, CH-1015 Lausanne, Switzerland.

9 d Department of Biology, Stanford University, Stanford, CA 94305-5020, USA.

$10{ }^{\mathrm{e}}$ UMR 5023 Écologie des Hydrosystèmes Naturels et Anthropisés, Université de Lyon 1, ENTPE, 11 CNRS, F-69622 Villeurbanne, France.

12 f School of Life Sciences, École Polytechnique Fédérale de Lausanne, CH-1015 Lausanne, 13 Switzerland.

14 nalcala@stanford.edu

15 severine.vuilleumier@epfl.ch

16 jean.secondi@univ-angers.fr

18 * Corresponding author at: La Maison du Lac de Grand-Lieu, rue du Lac, 44830 Bouaye, France (tel:

19 +33249109002; email: chaput_bardy_audrey@ @otmail.com or

20 a.cadou@maisondulacdegrandlieu.com)

21

$22 \dagger$ Both authors contributed equally.

$23 \mp$ Both authors supervised the research project. 
ABSTRACT

Forecasting the colonization process is important for wildlife managers who supervise the reintroduction of endangered species or control the spread of invasive species. Patch connectivity is thus critical to predicting the fates of expanding populations. Connectivity in river networks results from river dendritic structure and dispersal modality of organisms. Both factors may strongly affect the colonization process and the efficiency of conservation action plans. Based on empirical data, we simulated, using a simplified model with limited number of parameters, the colonization of a large river network, the Loire River, by the native Eurasian beaver and the invasive African clawed frog. For each species, we inferred model parameters (dispersal behavior and distances) by comparing the simulated and the observed distributions. Using network theory, we evaluated the efficiency of alternative conservation strategies to prevent or promote colonization of the river network. Network robustness to fragmentation and disturbance was also assessed. The model accurately predicted more than $70 \%$ of the observed species ranges. Conservation strategies that selectively protect habitat patches with the highest connectivity values provide a weak advantage at preventing connectivity loss compared to random protection strategies. In contrast, the targeted destruction of highly connected patches had a much stronger effect on the fragmentation of the network than the random removal of habitat patches. Spatial network topology strongly contributes to determining colonization patterns of large river watersheds. Network theory allows tests for robustness of rivers to fragmentation and disturbance, and identification of strategies for conservation planning.

Keywords: connectivity, conservation biology, dispersal, freshwater species, graph theory, river 
A major challenge in conservation biology is to predict population persistence. Such predictions are often difficult as they rely on the spatial divisions of populations, dispersal patterns, and the interaction between species of interest and landscape structure. These issues can be addressed by modeling populations into a network of habitat patches that are connected through edges (i.e. connectivity links) depending on the dispersal pathways of individuals (Baguette et al., 2013; Calabrese and Fagan, 2004; Crooks and Sanjayan, 2006; Moilanen and Nieminen, 2002). River networks are particularly challenging to model as a network of habitat patches. Their dendritic and hierarchical structures, as well as the directionality of water flow, bias the movements of individuals so that spatially close watercourses can be isolated from each other (Campbell Grant et al., 2007; Fagan, 2002; Samia et al., 2015). Furthermore, upstream disturbances can affect distant downstream populations because of asymmetric movements of individuals from headwaters to mainstreams (Vuilleumier and Possingham, 2006) but bias can also occur in other directions (Vuilleumier et al., 2010). Consequently, the effects of local environmental changes can propagate along the river network and have a greater impact on the overall connectivity than in most terrestrial environments (Fagan, 2002).

Not all freshwater organisms move strictly along the watercourses, though. Many species use two dispersal pathways in river networks: along the river watercourses and overland (between watercourses). Either of these can drastically alter the estimates of connectivity among habitat patches and other critical estimates like habitat occupancy or population persistence. These alternative dispersal behaviors are well documented empirically (Campbell Grant et al., 2010, 2007) but are seldom implemented in the design of wildlife management plans.

The use of network theory as a means of modeling metapopulation dynamics and connectivity in river networks is promising for the management of freshwater ecosystems (Campbell Grant et al., 2007; Erös et al., 2011a, 2011b; Fagan, 2002). By definition, a network is a set of nodes (points) connected by edges (links). In metapopulation ecology, nodes represent suitable habitat patches and edges potential pathways or corridors for dispersal (e.g. Baguette et al., 2013; Minor and Urban, 2008; Urban and Keitt, 2001). Using conceptualized representations of metapopulations as networks, various measures characterizing critical aspects of population viability can be estimated. For example, the metapopulation capacity of a fragmented landscape has been derived from the network centrality measure (Hanski and Ovaskainen, 2000). Network metrics have also been used to estimate population abundance and persistence (Webb et al., 2013). Among them, connectivity indices can quantify the importance of a habitat patch for dispersal within the network by quantifying how frequently a habitat patch is used as an intermediate step between other habitat patches during dispersal (e.g. the betweenness centrality, Erös et al., 2011a). In addition, the range expansion of a population can be characterized by measuring how large a network is (e.g., using the diameter of the network, Barták et al., 2013; Rayfield et al., 2011). The effect of habitat fragmentation on connectivity can also be quantified using metrics such as the probability of connectivity, $P C$ (Saura and Pascual-Hortal, 2007). PC quantifies the amount of reachable habitat in the landscape by accounting for the connectivity both within and between groups of connected habitat patches (Saura, et al., 2014; Saura and Pascual-Hortal, 2007). Finally, network analysis algorithms allow for testing both the robustness to fragmentation and the resilience to disturbance of population networks by assessing network properties (summarized by network metrics) as nodes are removed in increasing numbers (Barabasi and Bonabeau, 2003; Fortuna et al., 2006; Minor and Urban, 2008). 
Here, we present a method to select management strategies for conservation in river networks. Our method generates spatial networks that account for different dispersal behaviors (along watercourses and/or overland). Firstly, we investigated how dispersal behavior associated with the dendritic structure of river network influences connectivity between habitat patches and colonization in a river network. To do so, we simulated the colonization of the Loire River drainage by a reintroduced species, the Eurasian beaver Castor fiber (Linnaeus 1758) and an invasive species, the African clawed frog Xenopus laevis (Daudin 1802). The former species disperses along watercourses (Fustec et al., 2001; Halley and Rosell, 2002; Heidecke, 1984; Saveljev et al., 2002), while the latter disperses along watercourses and overland (Fouquet and Measey, 2006; Lobos and Jaksic, 2005). We simulated the expected distribution of both species along the river network for various dispersal distances. Simulation results were then compared to the observed distributions, and value of dispersal distances were estimated for each species based on the true skill statistic (Allouche et al., 2006). Secondly, using inferred dispersal distances for each species, we quantified the effectiveness of management strategies in either promoting (relevant for species of conservation interest) or limiting (relevant for invasive species) colonization of the network. Finally, we provide guidelines as to what may promote or impede colonization of large river networks and discusses general interest in the use of network theory to design conservation and management action plans at the scale of the river network.

\section{Materials and methods}

\subsection{Modeling approaches}

Our goal was to simulate the invasion processes that have led to the observed species distributions in the Loire River for the Eurasian beaver and the African clawed frog. Available data included (1) the introduction points and (2) the current distribution. To simulate the species' extension through the network, we used a dynamic model that considered successive colonization events generating occupied habitat patches in the river network. From this model, we inferred dispersal distance for the two species in an effort to reproduce the observed distribution. Then, to evaluate different management actions, we considered the currently observed distributions and the inferred dispersal distances. We thus consider first a dynamic model that uses historical range expansion to estimate dispersal and second a (stationary) equilibrium model that utilizes current distributions to evaluate management actions.

\subsection{Model of the river network}

The river network was modeled as a set of habitat patches (nodes) regularly distributed along the river and a set of edges (corridors) that connect habitat patches (Fig. 1a). The number and distributions of edges within the network depended on the river topology and the dispersal behavior of each species: dispersal occurs along the watercourse (in-stream dispersal, Fig 1b) for the Eurasian beaver and along the watercourse but also overland for the African clawed frog (in-stream and overland dispersal Fig 1b). We thus obtained two networks differing in connectivity patterns. These networks were used first to simulate species colonization and second to compare those simulations with the observed distribution of each species in the network. For the latter, habitat patches were considered occupied or unoccupied according to the observed species distribution in the river watershed. 
Our aim was to simulate the current focal species' distributions given their introduction site along the river, accounting for both the spatial structure of the habitat and the dispersal abilities of the species. To do so, we simulated colonization along the river using a stochastic patch occupancy model (SPOM; see review in Hanski and Ovaskainen, 2003). Under SPOMs, the habitat is subdivided into a finite number of habitat patches, and only the presence or absence of the focal species is modelled, not its local dynamics. Colonization along the river then occurred as a succession of colonization events from occupied habitat patches. Our model quantified the dynamics of occupied and unoccupied habitat patches, thus following the metapopulation paradigm (Levins, 1969) commonly used in conservation biology (Bascompte and Solé, 1998; Hanski and Ovaskainen, 2000). However, in our model we only simulated the colonization process and did not consider the metapopulation dynamics per se (i.e., extinction-colonization dynamics), because extinction events were not likely to be important in the time scale investigated, and because we were interested in the expansion of the species in the network and the control of this expansion. The colonization process is characterized by a unique parameter that represents the maximal dispersal distance and depends on the presence of unoccupied habitat within this range. One critical advantage of this approach is the limited number of model parameters - which are often difficult to estimate. Such an approach has proven successful in describing large-scale population dynamics and the design of conservation plans (Akçakaya et al., 2007).

Under the SPOM, the state of occupancy of patch $i$ is denoted $p_{i}$, where $p_{i}$ is 1 if patch $i$ is occupied, and 0 otherwise. We considered a colonization process, where empty patches could become occupied, but occupied patches could not become unoccupied, so the number of empty patches decreased through time. Following Hanski (1994), the connectivity of patch $i$, denoted $S_{i}$, followed:

$$
S_{i}=\sum_{j} m_{i j} p_{j} A_{j} \text { (1) }
$$

Where $m_{i j}$ is 1 when habitat patches $i$ and $j$ are within the species dispersal distance and 0 otherwise. We assumed that habitat patches have the same sizes and thus $A_{j}=1$ for all $j$. We considered time to be continuous, and that the rate at which an empty patch $i$ is colonized was proportional to $S_{i}$, with proportionality constant $c$. The process simulated was thus a continuous-time Markov chain, and the waiting time for a change in habitat patch occupancy was exponentially distributed with rate $\sum_{j} c S_{j}\left(1-p_{j}\right)$, where terms in $\left(1-p_{j}\right)$ ensured that only empty patches could be colonized. The probability of colonization of habitat patch $i$ was thus

$$
C_{i}=\frac{c S_{i}\left(1-p_{i}\right)}{\sum_{j} c S_{j}\left(1-p_{j}\right)}=\frac{S_{i}\left(1-p_{i}\right)}{\sum_{j} S_{j}\left(1-p_{j}\right)}(2)
$$

Interestingly, the constant $c$ from the numerator and the denominator cancel out in eq. 2; as a result, we can compute the probability of colonization of all habitat patches without knowing the actual colonization rate. This reduces the number of model parameters and makes our model robust to estimation error in the colonization rate.

Simulation of the colonization process was a random process that relied, from eqs. 1 and 2, on the matrix $\boldsymbol{M}=\left[m_{i j}\right]$, representing the network of habitat patches and the occupancy vector $\vec{p}=$ 
the introduction site of the focal species and $p_{j}=0$ for all other habitat patches $j, j \neq i$. Then, at each step of the simulation, a new empty habitat patch was colonized. This habitat patch was randomly selected among habitats within the dispersal distance of the species according to their colonization probability $C_{j}$, where greater $C_{j}$ values indicate a higher probability of being selected i.e. the colonized habitat patch was selected randomly [0-1] among the normalized distribution of $C_{j}$. Therefore, an empty habitat patch could be colonized only when located within the range (dispersal distance) of an occupied patch. Its probability of being colonized increases with the number of occupied patches present in its range (defined by the dispersal distance). Thus, in the model, a unique number, the maximal dispersal distance, characterized colonization. Dispersal was thus uniform within its range and modeled without kernel structure, an assumption that has been shown to be robust when evaluating management scenarios (Chadès et al., 2011). Colonization proceeded as long as the number of occupied patches $\sum_{i} p_{i}$ was less than the observed number of occupied patches for the focal species. The algorithm was implemented in $\mathrm{R}$ (R Core Team). This simulation was replicated 100 times for each dispersal distance.

\subsection{Comparison of simulated and observed ranges}

To compare the simulated and observed distributions of the species in the network, and to estimate the species' dispersal distances we calculated the species range (Barták et al., 2013). The species range was defined as the length of the union of all the shortest paths between pairwise occupied habitat patches (Barták et al., 2013). We also considered the size of the species range, which was defined as the number of habitat patches included in the species range. We further estimated the predictive accuracy of the correspondence between observed and simulated species distributions by computing the true skill statistic (TSS) as proposed by Allouche et al. (2006). The TSS is defined as follows:

$$
\text { TSS }=\text { sensitivity }+ \text { specificity }-1,
$$

with sensitivity being the proportion of observed presences that are predicted as such and the specificity being the proportion of observed absences that are predicted as such. Sensitivity thus accounts for omission errors, taken as the size of the union of observed and simulated ranges, divided by the size of the observed range. Likewise, specificity includes commission errors. In our case the specificity corresponded to the size of the union of observed and simulated patches outside the species range, divided by the observed number of patches outside of the range.

TSS values range from -1 to +1 , where a value of 1 predicts a perfect agreement between observed and simulated species distributions, and a value equal to or less than 0 signals a performance no better than random. As for our investigations, where we evaluated increasing values of dispersal distance, we expected sensitivity to converge to a constant value. The number of occupied habitat patches increased with dispersal distance, as did the proportion of overlap between observed and simulated presences. However, the specificity decreased with increasing dispersal distance, because the proportion of observed absences that were predicted as such decreased. There was thus a maximum value for the TSS, which could be identified by considering the value of the slope of the TSS.

\subsection{Measures of connectivity}

We quantified the connectivity in the network with two measures: the betweenness centrality, as a local measure of connectivity (i.e., contribution of a habitat patch to the network), and the 
probability of connectivity $(P C)$ of habitat patches, as a global measure of connectivity (i.e., whole network). Betweenness centrality measures the number of times a given habitat patch acts as a "bridge" along the shortest path between two other habitat patches, considering all pairs of patch in the network (Freeman, 1978), and is given as:

$$
B_{i}=\sum_{s \neq i, t \neq i} \frac{v_{s, t}^{i}}{v_{s, t}}
$$

where $v_{s, t}^{i}$ is the number of paths from patch $s$ to patch $t$ that pass through patch $i$ and $v_{s, t}$ is the total number of paths from patch $s$ to patch $t$. Betweenness centrality $\left(B_{\mathrm{i}}\right)$ has values between 0 and 1 , which indicates the importance of a given patch in the transfer of information (here individuals) between other patches of the network (Estrada and Bodin, 2008). This measure has been used to highlight major routes for dispersal (Estrada and Bodin, 2008; Minor and Urban, 2007; Urban et al., 2009). $B_{\mathrm{i}}$ scores were computed between all pairs of habitat patches in each network generated and for each dispersal distance. Because networks associated with the two species have different numbers of edges, we did not compare the absolute scores across networks. Instead, we used the Jenks' Natural Breaks algorithm (Jenks, $1963)$ to classify each habitat patch as having a high, medium or low value of $B_{\mathrm{i}}$. The probability of connectivity characterizes how important the surrounding of a habitat patch is in relation to the whole network. It specifically computes the probability that two randomly chosen habitat patches are reachable from one other (Saura and Pascual-Hortal, 2007). PC was computed as follows for a network composed of $n$ habitat patches:

$$
P C=\frac{\sum_{i} \sum_{j} m_{i j}^{*}}{(n-1)^{2}}
$$

where $m_{i j}^{*}=1$ if there is a path between nodes $i$ and $j$, and 0 otherwise and $m_{i i}^{*}=0$ for all $i$. $P C$ ranges from 0 (when all habitat patches are isolated) to 1 (when no patches are isolated). $P C$ can also be interpreted as a prediction of the colonization process, because it corresponds to the proportion of habitat that would be colonized if the colonization simulations were run long enough for the species to occupy its entire reachable habitat.

\subsection{Management strategies and their assessment}

We assessed four management strategies designed either to promote colonization of a species of conservation interest or to control the expansion of an invasive species. The first two conservation strategies would protect habitat patches of the river network either randomly the random protection strategy - or by targeting habitat patches with the highest betweenness centrality scores - the targeted protection strategy. The proportion of protected habitat patches in the network varied between $0.5 \%$ and $10 \%$. We then evaluated the performance of both conservation strategies by progressively removing habitat patches from the network at random until $80 \%$ of the habitat patches were removed. For the two control strategies, no habitat patch was protected, and habitat patches were progressively removed from the network until $80 \%$ were gone. Similar procedures to those described above were used to remove the habitat patch either at random - the random control strategy, or according to habitat patch betweenness centrality scores - the targeted control strategy - in which patches with the highest scores were removed first.

We evaluated the relative efficiency of the four above-described management strategies to maintain network connectivity by assessing resilience of the network in relation to habitat 
removal (Albert et al., 2000). A network was assumed to be robust and resilient if increasing the loss of patches did not decrease the $P C$ value. Finally, we computed the minimum number of habitat patches needing to be removed to reduce by half the initial value of $P C$, denoted $\alpha_{\text {min }}$ :

$$
\alpha_{\text {min }}=\min \left\{\alpha \in\{0,1, \ldots, n\} \mid \frac{P C_{\alpha}}{P C_{0}} \leq 0.5\right\},
$$

where $P C_{\alpha}$ is the value of $P C$ following the removal of $\alpha$ habitat patches and $P C_{0}$ is the initial value of $P C$, without habitat patch removal. We reported the median value of $\alpha_{\min }$ across the 1000 replicates.

Wilcoxon signed-rank tests were carried out between strategies (random versus targeted), across different dispersal distances, and for different proportions of habitat patch protection ( $0.5 \%$ to $10 \%$ when applies).

Network analyses and computation of connectivity indices were computed using the package igraph (Csardi and Nepusz, 2006) available in R (R Core Team).

\subsection{Case study: a protected and an invasive species in a large river network}

We retrieved the spatial distribution of waterways (excluding rivulets) of the Loire River (Appendix A, Fig. A1) from the French national hydrographical database (BD CARTHAGE® 2011, http://www.sandre.eaufrance.fr/). The river network was then modeled as 18084 habitat patches distributed along the river network and connected by edges $1 \mathrm{~km}$ in length. For the beaver, supplementary simulations were conducted restricting colonization processes to the mainstream and its main tributaries with Strahler order greater than 1 (Strahler, 1957); this network was referred as the 'main network' and will be compared to the 'whole network'.

The distributions of the Eurasian beaver and the African clawed frog on the Loire River were provided by the French National Agency for Wildlife (ONCFS). In particular, the presenceabsence data from the Loire River watershed was utilized (Appendix A, Fig. A2 and A3). We considered 399 habitat patches that were occupied by the Eurasian beaver and 57 habitat patches for the African clawed frog.

We compared the observed species distributions with simulated ones under different dispersal scenarios. Observed distributions were obtained by assigning the observed species occurrences to habitat patches and edges in the spatial river network (overlap). We explored a wide range of dispersal distances for both species, from 2 to $200 \mathrm{~km}$ for beavers along watercourses and from 1 to $20 \mathrm{~km}$ overland and along watercourses for African clawed frogs. Chosen distances and dispersal abilities encompass expected dispersal values for both species. Indeed, beavers have been shown to disperse over long distance in rivers, with observed dispersal distances varying from a few kilometers to $170 \mathrm{~km}$ (Heidecke, 1984; Saveljev et al., 2002). The longest dispersal distance recorded on the Loire River for the European beavers is $80 \mathrm{~km}$ (Fustec et al., 2001; Halley and Rosell, 2002). The African clawed frog was estimated to spread between water bodies at a rate between $3.1 \mathrm{~km} /$ year and $5.4 \mathrm{~km} /$ year (Lobos and Jaksic, 2005), and the colonization rate of the Loire River watershed is estimated at $1 \mathrm{~km} /$ year (Fouquet and Measey, 2006). In the simulations, each species was 'introduced' into the patch nearest to their documented introduction site, close to Blois for beavers $\left(47^{\circ} 35^{\prime} 38^{\prime \prime} \mathrm{N}\right.$, $\left.1^{\circ} 19^{\prime} 41^{\prime \prime E}\right)$ and Bouillé Saint Paul for frogs (47 $\left.1^{\prime} 33.96 " \mathrm{~N}, 0^{\circ} 20^{\prime} 42^{\prime \prime} \mathrm{W}\right)$. 


\section{Results}

\subsection{Network topology and colonization}

For both species, TSS values increased with dispersal distance, reaching a maximum value at a dispersal distance identified by the slope of the TSS values., namely when the TSS values are maximal and the slope is close to zero i.e. within [-0.003;0.003]. For the beaver, the maximum TSS value was reach when the dispersal distance was between $80 \mathrm{~km}$ to $180 \mathrm{~km}$ (Fig. 2a) for the whole network and between 120 and $180 \mathrm{~km}$ for the main network (Fig. 2b). For the African clawed frog, this distance was between $4 \mathrm{~km}$ and $10 \mathrm{~km}$. The maximal values of TSS are around 0.4 (whole network) and 0.7 (mainstreams) for the beaver, and 0.7 for the frog (Fig. 2). This means that up to $70 \%$ of the simulated range corresponded to the observed range, with up to $85 \%$ of the habitat patches correctly classified. According to TSS, simulations predicted the observed species distributions when dispersal was greater than 80 $\mathrm{km}$ for the Eurasian beaver and greater than $4 \mathrm{~km}$ for the African clawed frog.

We computed betweenness centrality scores for the observed occupancy patches for both species considering distances ranging from 80 to $180 \mathrm{~km}$ for the beaver and from 4 to 10 $\mathrm{km}$ for the frog. For the Eurasian beaver, which disperses in-stream, only $1 \%$ of habitat patches showed a high betweenness centrality (range 34 733-79 617), while 7\% showed a medium score (range 8 440-34 733). The patches with the highest centrality scores were located on the mainstreams in the center of the network (Fig. 3). For the African clawed frog, which disperses overland, $16 \%$ and $23 \%$ of patches showed high (range 210-523) and medium (range 63-210) betweenness centrality scores, respectively. Patches with the highest scores were scattered in the eastern part of the colonized area (Fig. 4) and were independent of the dispersal distance (from 4 to $10 \mathrm{~km}$ ). The patch scores were highly correlated across dispersal distances in both species (Spearman rank correlation test: Eurasian beaver $0.868<$ $\rho<0.916, \mathrm{p}<2 \mathrm{E}-16$; African clawed frogs $0.455<\rho<0.774, \mathrm{p}<1.024 \mathrm{E}-12$ ). Consequently, we only present results for an $80-\mathrm{km}$ dispersal distance in the beaver and 4-km dispersal distance in the frog.

\subsection{Effect of management strategy on connectivity}

We assessed network robustness to fragmentation and resilience (i.e. the capacity to respond to perturbations) under the four management strategies described above: random protection, targeted protection, random control, and targeted control of patches.

Protection strategy - For each species, we observed an abrupt transition between high and low $P C$ values (Fig. 5 and 6). The percentage of removed patches required to reach the transition increased with dispersal distance. For the Eurasian beaver (Fig. 5), when considering $1 \%$ of protected patches, the transition occurs around $2 \%, 40 \%$ and $60 \%$ of removed patches, representing distances of $80 \mathrm{~km}, 120 \mathrm{~km}$ and $160 \mathrm{~km}$, respectively. Thus, network robustness increased with dispersal distance (Table 1). For the African clawed frog a much larger proportion of habitat patches $(40-60 \%)$ had to be removed to decrease the $P C$ value, and the effect of dispersal distance was weaker (Table 1). 
The percentage of protected patches did not significantly influence the changes in $P C$ values for either species (Fig. 5 and 6, Appendix A: Tables A1 and A2). For the beaver, when considering a $120 \mathrm{~km}$ maximum dispersal distance and $1 \%, 5 \%$ and $10 \%$ of protected patches, the transition occurred when $40 \%$ of the habitat patches were removed. We also found limited evidence of an effect of the protection strategy (random $v$ s targeted) on connectivity (Table 2). Although the percentage of removed patches required to halve $P C$ median value was always higher in the protection strategy, we only detected a few significant effects in four cases (Table 2). Assuming a dispersal distance of $80 \mathrm{~km}$ for the beaver, we found that removing less than $1 \%$ of patches was sufficient for halving the $P C$ whatever the protection strategy. We also found that targeted protection was better than random protection when the percentage of protected patches reached $10 \%$. For the African clawed frog, halving the $P C$ required substantial habitat patch removal ( $48 \%$ to $89 \%$ ), and a significant difference between random and targeted strategies was observed when $10 \%$ of habitat patches were protected (assuming 6-km dispersal distance).

Control strategy - The number of removed patches necessary to halve the $P C$ values was lower under the targeted control strategy than under the random control strategy, regardless of species or dispersal distance. The effect was particularly strong in the Eurasian beaver under the targeted strategy (Fig. 7, Table 3). When using a targeted strategy, removing less than $10 \%$ of occupied patches for all dispersal distances considered $(80 \mathrm{~km}, 120 \mathrm{~km}$ and $160 \mathrm{~km})$ was enough to halve $P C$ (Fig. 7). On the contrary, for the African clawed frog, between $17.42 \%$ and $51.36 \%$ of patches had to be removed to halve $P C$ (Fig. 7, Table 3 ). The dispersal distance determined the transition between high and low $P C$ values, but in interaction with the control strategy applied and the species considered. For the beaver, $P C$ increased with dispersal distance for the random control strategy but it did not for the targeted control strategy. For the African clawed frog, results were very similar in all dispersal distances considered and in both strategies (Table 1), and robustness was significantly higher for the 8$\mathrm{km}$ dispersal distance than for the 4-km dispersal distance.

\section{Discussion}

\subsection{Forecasting the colonization of river networks}

Up to $70 \%$ of the distribution ranges of two species that colonized different parts of the same river network could be explained by simulating a simple colonization process. This result suggests that the topology of the river network plays an important role in predicting species distributions in riverine ecosystems (Bertuzzo et al., 2009; Campbell et al., 2007; Fagan, 2002). This result is also important for management issues since the model as described here requires only a restricted number of parameters: network topology, range of dispersal distances, and dispersal behavior. Though many factors are expected to influence connectivity (and ultimately species dispersal and range size) such as environmental gradients, landscape structure, and local habitat quality (Peterson et al., 2013), we found that for both species the networks' geometric configuration seemed to be the major predictor of the colonization process.

It is also noteworthy that the observed and simulated ranges matched more closely for longdispersal distances (i.e., $>80 \mathrm{~km}$ for the beaver and $>3 \mathrm{~km}$ for the African clawed frog). For 
the Eurasian beaver, this dispersal distance is consistent with maximal empirical estimates of dispersal on the Loire River (Fustec et al., 2001), and is in the higher range of commonly measured dispersal distances in other waterways for this species (Saveljev et al., 2002) or for the Canadian beaver, Castor canadensis (Sun et al., 2000). For the African clawed frog, the colonization front has been estimated to shift at a speed of $1 \mathrm{~km} /$ year (Fouquet and Measey, 2006). Therefore, colonization may have been strongly influenced by (rare) long-dispersal events in both species.

An important feature of our method is its ability to compare species distributions and estimate dispersal distances from a single time-point, and without knowing the actual colonization rate of the species. It might thus allow the study of many invasive species for which data is scarce and colonization dynamics are unknown.

\subsection{Assessing the efficiency of alternative strategies}

Our second objective was to assess the efficiency of four management strategies that either target or ignore protection or destruction of central habitat patches. Contrasting results were found between strategies, but consistent ones arose across species. We found no effect of the protection strategy (random $v s$ targeted) on network connectivity ( $P C$ values), even when $10 \%$ of habitat patches were protected; this effect was weak in both species except when dispersal distances were short and at least $10 \%$ of the habitat patches were protected. Otherwise, we observed a strong overlap of simulation results with observed results. The targeted habitat patch removal strategy had a much greater impact on the reduction of connectivity at the network scale than the random one, regardless of dispersal behavior and species. We observed that the habitat patch network was sensitive to targeted attacks and was relatively robust to the random loss of habitat patches. Removing the patches with the highest betweenness centrality scores rapidly split the network into isolated sub-units. This result suggested that the targeted control strategy may be an efficient management option in river ecosystems for a large number of invasive species with contrasting dispersal characteristics. However, increasing dispersal distances tended to buffer this effect (Cushman et al., 2010). The actual efficiency of the targeted control strategy may thus depend on the frequency of long-distance dispersal events of the focal species.

\subsection{Characterizing the importance of habitat patches within a river network}

Our results emphasize that habitat spatial arrangement and dispersal behavior are jointly critical in estimating connectivity in river watersheds (Campbell Grant et al., 2007). Indeed, the number and location of patches with the high connectivity (highest betweenness scores) depend directly on dispersal pathways, which are themselves determined by the topology of the network and species dispersal abilities (e.g., in-stream or overland dispersal). We observed that patches were more weakly connected for the beaver (in-stream dispersal) than for the frog (overland dispersal). This discrepancy had consequences on the efficiency of management strategies. For the Eurasian beaver, over $37 \%$ of patches did not contribute to network connectivity (had a null betweenness centrality score), and protecting targeted patches with high betweenness centrality scores did not significantly improve robustness of the network, results that held true considering different dispersal abilities. We observed better performance, even if differences were not significant, of the targeted strategy over the random strategy. This result may be worthy of consideration in future conservation strategies. However, the conservation benefit may be marginal with regards to the costs of implementing this strategy, as the constraint of selecting specific patches rather than random patches might carry additional costs (renting/buying land, site restoration, etc.). This slight advantage of the 
targeted strategy over the random strategy is thus an important finding for management, as it alleviates constraints on the choice of sites to protect.

Considering the control of expanding African clawed frog populations, network robustness for this species was high and up to $40 \%$ of random patches had to be removed before a change in connectivity was observed. In contrast, the network was split much more efficiently when highly connected patches were first removed (target control). The management of the African clawed frog thus seems difficult, as a large number of patches need to be controlled to reduce network connectivity. It is interesting to note that very long-dispersal distances would not necessary affect management efficiency in this case and that although overland dispersal offers more pathways to connect habitat patches than in-stream dispersal, the topology of the network appears critical for the connectivity between habitat patches.

\subsection{A model with limited parameter for the management of populations in river networks and limits}

Using a limited set of parameters (dispersal abilities and habitat patch distribution), we did not expect a perfect match between the simulated ranges and the actual distributions of our focal species. Discrepancies were necessarily caused by local, historical, or present-day factors. In order to obtain better fits, information on habitat quality (Carranza et al., 2011; Urban and Keitt, 2001; Van Looy et al., 2013), population dynamics (growth rate, population size and structure, Neeson et al., 2012), dispersal (kernel or rate, Cushman et al., 2013) and landscape structure in the colonized range (Radinger and Wolter, 2015) would be required. However, reaching this level of precision requires a deep knowledge of species' ecology and behavior and high quality environmental data, none of which are consistently available, namely due to time and budget constraints. In contrast, our approach requires limited ecological investigation and may allow rapid implementation of action plans. This feature is particularly desirable for the control of fast spreading invasive populations. More generally, identifying the central patches that maximize population connectivity is crucial for maintaining metapopulation systems, optimizing reintroduction success, or cutting short biological invasions. The management strategies tested here were either targeted or random relative to the central habitat patches. We considered habitat patches with the highest betweenness centrality scores to be central. While such approaches have been shown to poorly perform in small networks, they are recommended for large and complex ones (Chadès et al., 2011). Using other heuristic search methods, such as simulated annealing or genetic algorithms, might have improved the identification of central habitat patches in our network (Ascough et al., 2008) but would have required different functions to be optimized for each of the scenarios investigated (Nicol et al., 2010). River networks generate heterogeneity in suitability (habitat $v s$ non habitat), and their spatial structure can be easily extracted and used to simulate dispersal and colonization processes. Our study shows that spatial network analysis is an effective tool to predict the expansion of a population, to identify highest priority patches, and to select between alternate strategies for conservation planning in river drainages.

\section{Acknowledgements}


The authors thank the editor and reviewers whose comments and suggestions greatly improved the manuscript. We also thank Kristen Irwin for a careful reading of the manuscript. This work was funded by the "Plan Loire Grandeur Nature" and the European Regional Development Fund to JS and ACB, and by the Swiss National Science Foundation grants no.PMPDP3158381 to SV.

\section{References}

Akçakaya, H.R., Mills, G., Doncaster, C.P., 2007. The role of metapopulations in conservation, in: Macdonald, D., Service, K. (Eds.), Key Topics in Conservation Biology. Blackwell Publishing, Oxford, UK, pp. 64-84. doi:10.1002/jcp.22422

Albert, R., Jeong, H., Barabasi, A.-L., 2000. Error and attack tolerance of complex networks. Nature 406, 378-382. doi:10.1038/35054111

Allouche, O., Tsoar, A., Kadmon, R., 2006. Assessing the accuracy of species distribution models: Prevalence, kappa and the true skill statistic (TSS). J. Appl. Ecol. 43, 12231232. doi:10.1111/j.1365-2664.2006.01214.x

Ascough, J.C., Maier, H.R., Ravalico, J.K., Strudley, M.W., 2008. Future research challenges for incorporation of uncertainty in environmental and ecological decision-making. Ecol. Model. 219, 383-399. doi.org/10.1016/j.ecolmodel.2008.07.015

Baguette, M., Blanchet, S., Legrand, D., Stevens, V.M., Turlure, C., 2013. Individual dispersal, landscape connectivity and ecological networks. Biol. Rev. Camb. Philos. Soc. 88, 310-326. doi:10.1111/brv.12000

Barabasi, A.-L., Bonabeau, E., 2003. Scale-free networks. Sci. Am. 288, 60-69.

Barták, V., Vorel, A., Š́mová, P., Puš, V., 2013. Spatial spread of Eurasian beavers in river networks: A comparison of range expansion rates. J. Anim. Ecol. 82, 587-597. doi:10.1111/1365-2656.12040

Bascompte, J., Solé, R.V., 1998. Modeling spatiotemporal dynamics in ecology. Springer, NewYork.

Bertuzzo, E., Muneepeerakul, R., Lynch, H.J., Fagan, W.F., Rodriguez-Iturbe, I., Rinaldo, A., 2009. On the geographic range of freshwater fish in river basins. Water Resour. Res. 45, 1-11. doi:10.1029/2009WR007997

Campbell Grant, E.H., Lowe, W.H., Fagan, W.F., 2007. Living in the branches: population dynamics and ecological processes in dendritic networks. Ecol. Lett. 10, 165-75. doi:10.1111/j.1461-0248.2006.01007.x

Campbell Grant, E.H., Nichols, J.D., Lowe, W.H., Fagan, W.F., 2010. Use of multiple dispersal pathways facilitates amphibian persistence in stream networks. Proc. Natl. Acad. Sci. U. S. A. 107, 6936-6940. doi:10.1073/pnas.1000266107

Carranza, M.L., D’Alessandro, E., Saura, S., Loy, A., 2011. Connectivity providers for semiaquatic vertebrates: the case of the endangered otter in Italy. Landsc. Ecol. 27, 281-290. doi:10.1007/s10980-011-9682-3

Chadès, I., Martin, T.G., Nicol, S., Burgman, M., Possingham, H.P., Buckley, Y., 2011. General rules for managing and surveying networks of pests, diseases and endangered species. P. Natl Acad. Sci. USA 108: 8323-8328. doi/10.1073/pnas.1016846108 
Csardi, G., Nepusz, T., 2006. The igraph software package for complex network research. InterJournal Complex Syst. 1695.

Cushman, S.A., Compton, B.W., Mcgarigal, K., 2010. Habitat fragmentation effects depend on complex interactions between population size and dispersal ability: Modeling influences of roads, agriculture and residential development across a range of life-history Characteristics, in: Cushman, S.A., Huettmann, F. (Eds.), Spatial Complexity, Informatics, and Wildlife Conservation. Springer, New York, pp. 367-383. doi:10.1007/978-4-431-87771-4

Cushman, S.A., Landguth, E.L., Flather, C.H., 2013. Evaluating population connectivity for species of conservation concern in the American Great Plains. Biodivers. Conserv. 22, 2583-2605. doi:10.1007/s10531-013-0541-1

Erős, T., Olden, J.D., Schick, R.S., Schmera, D., Fortin, M.-J., 2011a. Characterizing connectivity relationships in freshwaters using patch-based graphs. Landsc. Ecol. 27, 303-317. doi:10.1007/s10980-011-9659-2

Erős, T., Schmera, D., Schick, R.S., 2011b. Network thinking in riverscape conservation - A graph-based approach. Biol. Conserv. 144, 184-192. doi:10.1016/j.biocon.2010.08.013

Estrada, E., Bodin, O., 2008. Using network centrality measures to manage landscape connectivity. Ecol. Appl. 18, 1810-1825. doi:10.1890/07-1419.1

Fagan, W., 2002. Connectivity, fragmentation, and extinction risk in dendritic metapopulations. Ecology 83, 3243-3249. doi:10.1890/00129658(2002)083[3243:CFAERI]2.0.CO;2

Fortuna, M.A., Gomez-Rodriguez, C., Bascompte, J., 2006. Spatial network structure and amphibian persistence in stochastic environments. Proc. R. Soc. B Biol. Sci. 273, 14291434. doi:10.1098/rspb.2005.3448

Fouquet, A., 2001. Des clandestins aquatiques. Zamenis 6, 10-11.

Fouquet, A., Measey, G.J., 2006. Plotting the course of an African clawed frog invasion in Western France. Anim. Biol. 56, 95-102. doi:10.1163/157075606775904722

Freeman, L., 1978. Centrality in social networks conceptual clarification. Soc. Networks 1, 215-239. doi:10.1016/0378-8733(78)90021-7

Fustec, J., Lode, T., Le Jacques, D., Cormier, J.P., 2001. Colonization, riparian habitat selection and home range size in a reintroduced population of European beavers in the Loire. Freshw. Biol. 46, 1361-1371. doi:10.1046/j.1365-2427.2001.00756.x

Halley, D., Rosell, F., 2002. The beaver's reconquest of Eurasia: status, population development and management of a conservation success. Mamm. Rev. 32, 153-178. doi:10.1046/j.1365-2907.2002.00106.x

Hanski, I. 1994. A practical model of metapopulation dynamics. J. Anim. Ecol. 63, 151-162. doi:10.2307/5591

Hanski, I., Ovaskainen, O. 2003. Metapopulation theory for fragmented landscapes. Theo. Popul. Biol. 64, 119-127. doi:10.1016/S0040-5809(03)00022-4

Hanski, I., Ovaskainen, O., 2000. The metapopulation capacity of a fragmented landscape. Nature 404, 755-758. doi:10.1038/35008063

Heidecke, D., 1984. Untersuchungen zur Okologie und Populationsentwicklung des Elbebibers Castor fiber albicus Matscie, 1907, Teil 1. Biologische und 
populationsokologische Ergebnisse. Zool. Jb. Syst. 111, 1-41.

Jenks, G.F., 1963. Generalization in Statistical Mapping. Ann. Assoc. Am. Geogr. 53, 15-26. doi:10.1111/j.1467-8306.1963.tb00429.x

Levins, R., 1969. Some demographic and genetic consequences of environmental heterogeneity for biological control. Bull. Entomol. Soc. Am. 15, 237-240. doi:10.1093/besa/15.3.237

Lobos, G., Jaksic, F., 2005. The ongoing invasion of African clawed frogs (Xenopus laevis) in Chile: causes of concern. Biodivers. Conserv. 14, 429-439. doi:10.1007/s10531-0046403-0

Minor, E.S., Urban, D.L., 2008. A graph-theory framework for evaluating landscape connectivity and conservation planning. Conserv. Biol. 22, 297-307. doi:10.1111/j.15231739.2007.00871.x

Minor, E.S., Urban, D.L., 2007. Graph theory as a proxy for spatially explicit population models in conservation planning. Ecol. Appl. 17, 1771-1782. doi:10.1890/06-1073.1

Moilanen, A., Nieminen, M., 2002. Simple connectivity measures in spatial ecology. Ecology 83, 1131-1145. doi:10.2307/3071919

Nicol, S.; Chadès, I.; Linke, S.; Possingham, H.P., 2010. Conservation decision-making in large state spaces. Ecol. Model. 221, 2531-2536. doi:10.1016/j.ecolmodel.2010.02.009

Neeson, T.M., Wiley, M.J., Adlerstein, S.A., Riolo, R.L., 2012. How river network structure and habitat availability shape the spatial dynamics of larval sea lampreys. Ecol. Model. 226, 62-70. doi:10.1016/j.ecolmodel.2011.11.031

Peterson, E.E., Ver Hoef, J.M., Isaak, D.J., Falke, J. a, Fortin, M.-J., Jordan, C.E., McNyset, K., Monestiez, P., Ruesch, A.S., Sengupta, A., Som, N., Steel, E.A., Theobald, D.M., Torgersen, C.E., Wenger, S.J., 2013. Modelling dendritic ecological networks in space: an integrated network perspective. Ecol. Lett. 16, 707-19. doi:10.1111/ele.12084

Radinger, J., Wolter, C., 2015. Disentangling the effects of habitat suitability, dispersal and fragmentation on the distribution of river fishes. Ecol. Appl. 25, 914-927. doi:10.1890/14-0422.1

Rayfield, B., Fortin, M., Fall, A., 2011. Connectivity for conservation: a framework to classify network measures. Ecology 92, 847-858. doi:10.1890/09-2190.1

Samia, Y, Frithjof L., Hastings A. 2015. Connectivity, passability and heterogeneity interact to determine fish population persistence in river networks. J R Soc Interface 12, 20150435. doi.org/10.1098/rsif.2015.0435

Saura, S., Bodin, Ö., Fortin, M.-J., 2014. Stepping stones are crucial for species' long-distance dispersal and range expansion through habitat networks. J. Appl. Ecol. 51, 171-182. doi:10.1111/1365-2664.12179

Saura, S., Pascual-Hortal, L., 2007. A new habitat availability index to integrate connectivity in landscape conservation planning: Comparison with existing indices and application to a case study. Landsc. Urban Plan. 83, 91-103. doi:10.1016/j.landurbplan.2007.03.005

Saveljev, A.P., Stubbe, M., Stubbe, A., Unzhakov, V. V, Kononov, S. V, 2002. Natural Movements of Tagged Beavers in Tyva. Russ. J. Ecol. 33, 460-465. doi:10.1023/A:1020911800651

Strahler, A.N., 1957. Quantitative analysis of watershed geomorphology. Trans. AUG 38, 

913-920. doi:10.1029/TR038i006p00913

Sun, L., Müller-Schwarze, D., Schulte, B.A, 2000. Dispersal pattern and effective population size of the beaver. Can. J. Zool. 78, 393-398. doi:10.1139/z06-029

Urban, D., Keitt, T., 2001. Landscape connectivity: a graph-theoretic perspective. Ecology 82, 1205-1218. doi:10.2307/2679983

Urban, D.L., Minor, E.S., Treml, E. a, Schick, R.S., 2009. Graph models of habitat mosaics. Ecol. Lett. 12, 260-73. doi:10.1111/j.1461-0248.2008.01271.x

Van Looy, K., Cavillon, C., Tormos, T., Piffady, J., Landry, P., Souchon, Y., 2013. A scalesensitive connectivity analysis to identify ecological networks and conservation value in river networks. Landsc. Ecol. 28, 1239-1249. doi:10.1007/s10980-013-9869-x

Vuilleumier S., Bolker B.M., Lévêque O., 2010. Effects of colonization asymmetries on metapopulation persistence. Theor. Popul. Biol. 78, 225-238. doi:10.1016/j.tpb.2010.06.007

Vuilleumier, S., Possingham, H.P., 2006. Does colonization asymmetry matter in metapopulations? Proc. R. Soc. Biol. Sci. Ser. B 273, 1637-42. doi:10.1098/rspb.2006.3469

Webb, J.A., Padgham.M., 2013. How does network structure and complexity in river systems affect population abundance and persistence? Limnologica 43, 399-403. doi:10.1016/j.limno.2013.04.006 
Table 1. Effect of management strategy and dispersal distance on network robustness for the Eurasian beaver and the African clawed frog. Differences between median values of probability of connectivity were tested using Wilcoxon signed-rank tests. Significant p-values after a Bonferroni correction are in bold ( $\mathrm{p}$-value $<0.00005$ ). Note that for protection strategies, results are reported for simulations where $0.5 \%$ of patches were protected.

\begin{tabular}{|c|c|c|c|c|c|}
\hline Species & Management strategy & & $\begin{array}{l}\text { Dispersal } \\
\text { distance } \\
(\mathrm{km})\end{array}$ & W & $p$-value \\
\hline \multirow{12}{*}{$\begin{array}{l}\text { Eurasian } \\
\text { beaver }\end{array}$} & \multirow{6}{*}{ Protection } & \multirow{3}{*}{ targeted } & 80 vs 120 & 50 & $<2.2 \mathrm{E}-16$ \\
\hline & & & 80 vs 160 & 36.5 & $<2.2 \mathrm{E}-16$ \\
\hline & & & $\begin{array}{l}120 \text { vs } \\
160\end{array}$ & 1093 & 7.4E-06 \\
\hline & & \multirow{3}{*}{ random } & 80 vs 120 & 178 & $<2.2 \mathrm{E}-16$ \\
\hline & & & 80 vs 160 & 50.5 & $<2.2 \mathrm{E}-16$ \\
\hline & & & $\begin{array}{l}120 \text { vs } \\
160\end{array}$ & 1121.5 & $3.8 \mathrm{E}-05$ \\
\hline & \multirow{6}{*}{ Control } & \multirow{3}{*}{ targeted } & 80 vs 120 & 2145.5 & 0.318 \\
\hline & & & 80 vs 160 & 2184.5 & 0.405 \\
\hline & & & $\begin{array}{l}120 \text { vs } \\
160\end{array}$ & 2414 & 0.888 \\
\hline & & \multirow{3}{*}{ random } & 80 vs 120 & 242 & $2.2 \mathrm{E}-16$ \\
\hline & & & 80 vs 160 & 92.5 & 2.2E-16 \\
\hline & & & $\begin{array}{l}120 \text { vs } \\
160\end{array}$ & 1517 & $9.4 \mathrm{E}-05$ \\
\hline \multirow{12}{*}{$\begin{array}{l}\text { African } \\
\text { clawed } \\
\text { frog }\end{array}$} & \multirow{6}{*}{ Protection } & \multirow[t]{3}{*}{ targeted } & 4 vs 6 & 906.5 & 0.002 \\
\hline & & & 4 vs 8 & 743.5 & 3.7E-06 \\
\hline & & & 6 vs 8 & 1100.5 & 0.040 \\
\hline & & \multirow{3}{*}{ random } & 4 vs 6 & 957.5 & 0.011 \\
\hline & & & 4 vs 8 & 735.5 & 6.7E-06 \\
\hline & & & 6 vs 8 & 1046 & 0.020 \\
\hline & \multirow{6}{*}{ Control } & \multirow[t]{3}{*}{ targeted } & 4 vs 6 & 801 & 0.0008 \\
\hline & & & 4 vs 8 & 585 & $9.4 \mathrm{E}-07$ \\
\hline & & & 6 vs 8 & 920 & 0.009 \\
\hline & & \multirow[t]{3}{*}{ random } & 4 vs 6 & 955.5 & 0.010 \\
\hline & & & 4 vs 8 & 732.5 & 6.0E-06 \\
\hline & & & 6 vs 8 & 1042 & 0.018 \\
\hline
\end{tabular}


Table 2. Effect of management strategies (targeted vs. random protections) on the robustness of the network colonized by the Eurasian beaver and the African clawed frog in the Loire River. Robustness was estimated using probability of connectivity $(P C)$. The percentage of removed patches for halving $P C$ is reported excepted when $P C$ did not decrease below 0.5 (in red). Differences between median values of $P C$ were tested using Wilcoxon signed-rank tests. Significant $\mathrm{p}$-values after a Bonferroni correction are in bold ( $\mathrm{p}$-value < 0.00005).

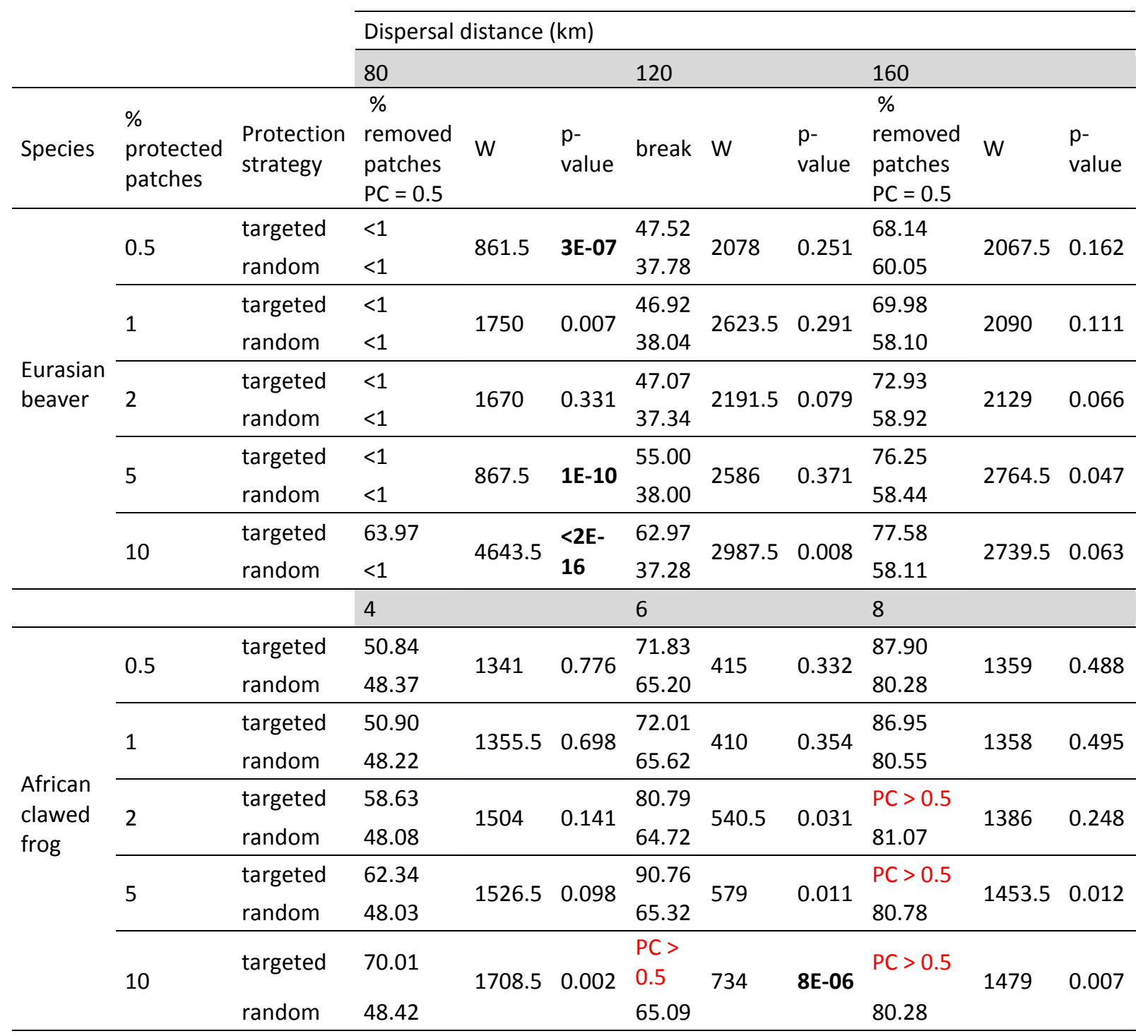


637 Table 3. Effect of management strategies (targeted vs. random control) on the robustness of 638 the network colonized by the Eurasian beaver and the African clawed frog in the Loire River. 639 Robustness was estimated using probability of connectivity $(P C)$. The percentage of removed 640 patches for halving the $P C$ is reported. Differences between median values of $P C$ were tested 641 using Wilcoxon signed-rank tests. Significant $p$-values after a Bonferroni correction are in 642 bold ( $\mathrm{p}$-value $<0.00005$ ).

643

\begin{tabular}{|c|c|c|c|c|c|}
\hline Species & $\begin{array}{l}\text { Dispersal } \\
\text { distance }(\mathrm{km})\end{array}$ & $\begin{array}{l}\text { Control } \\
\text { strategy }\end{array}$ & $\begin{array}{l}\text { \% removed patches } \\
P C=0.5\end{array}$ & w & $p$-value \\
\hline \multirow{3}{*}{$\begin{array}{l}\text { Eurasian } \\
\text { beaver }\end{array}$} & 80 & $\begin{array}{l}\text { targeted } \\
\text { random }\end{array}$ & $\begin{array}{l}<1 \\
<1\end{array}$ & 260.5 & $2.6 \mathrm{E}-16$ \\
\hline & 120 & $\begin{array}{l}\text { targeted } \\
\text { random }\end{array}$ & $\begin{array}{l}5.70 \\
38.22\end{array}$ & 203.5 & $<2.2 \mathrm{E}-16$ \\
\hline & 160 & $\begin{array}{l}\text { targeted } \\
\text { random }\end{array}$ & $\begin{array}{l}6.59 \\
59.09\end{array}$ & 207.5 & $<2.2 \mathrm{e}-16$ \\
\hline \multirow{3}{*}{$\begin{array}{l}\text { African } \\
\text { clawed frog }\end{array}$} & 4 & $\begin{array}{l}\text { targeted } \\
\text { random }\end{array}$ & $\begin{array}{l}17.42 \\
47.67 \\
\end{array}$ & 711 & $6.0 \mathrm{E}-06$ \\
\hline & 6 & $\begin{array}{l}\text { targeted } \\
\text { random }\end{array}$ & $\begin{array}{l}21.69 \\
65.02\end{array}$ & 646.5 & 4.1E-06 \\
\hline & 8 & $\begin{array}{l}\text { targeted } \\
\text { random }\end{array}$ & $\begin{array}{l}51.36 \\
80.55\end{array}$ & 837.5 & $1.2 \mathrm{E}-04$ \\
\hline
\end{tabular}


a

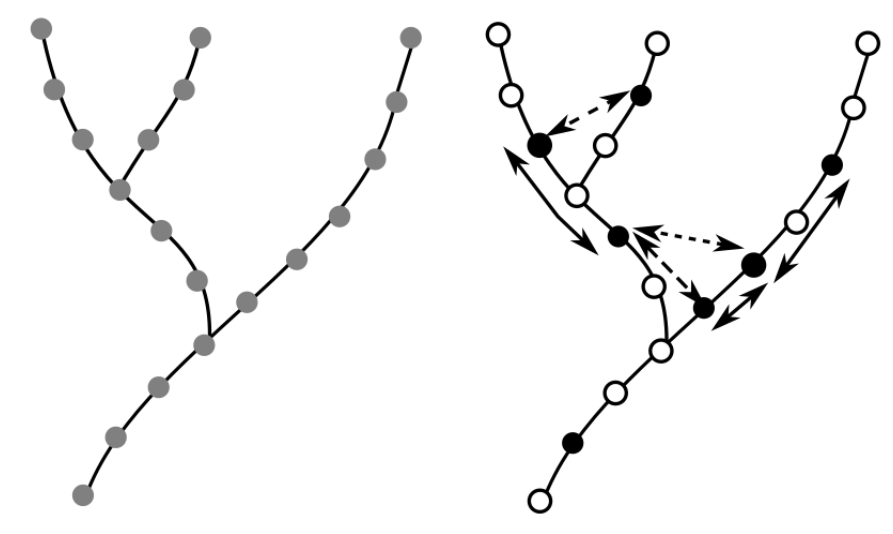

C

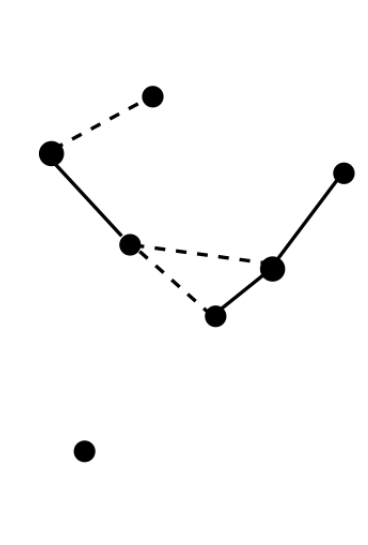

Fig. 1. The river network (a) was modeled as a set of connected spatial habitat patches (grey nodes). This network is converted into a presence-absence map (b) and into a graph according to the dispersal behavior of the species (c). The graph connectivity between occupied patches (black nodes) depended on dispersal behavior - in-stream (b, solid arrows) and overland (b, dotted arrows) - and dispersal distance. The graph (c) shows connections in-stream (solid lines) and overland (dotted lines) between occupied patches. 
a

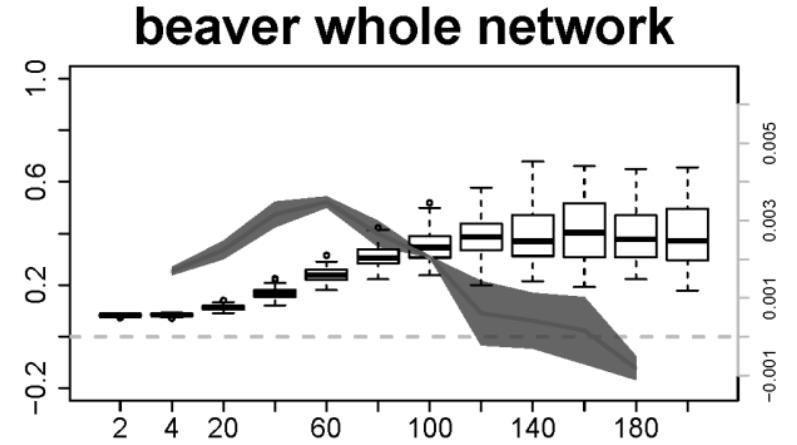

b beaver main network

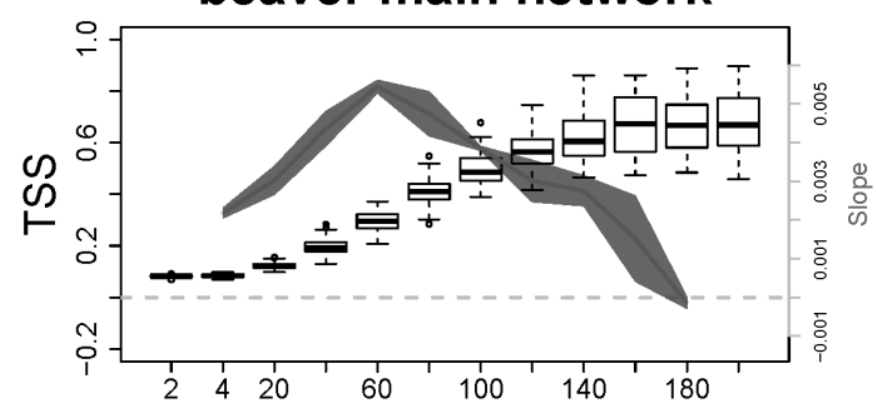

c frog whole network

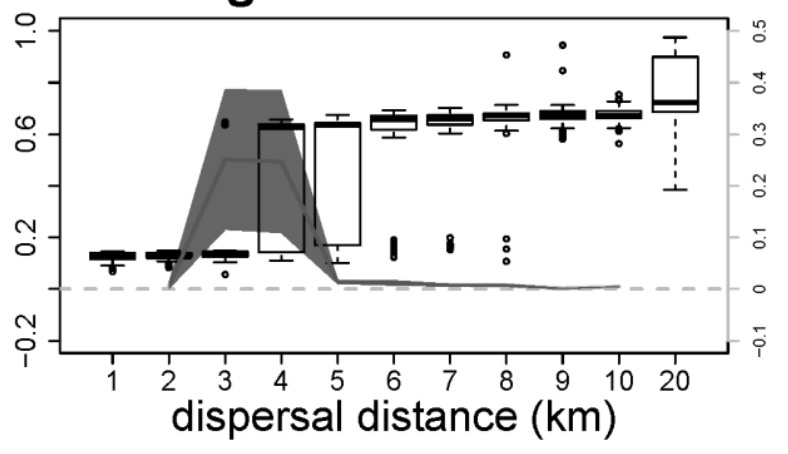

Fig. 2. Predictive accuracy of species distribution models according to TSS values (first axis) and corresponding slopes (second axis) across dispersal distances, in the Eurasian beaver (between 2 and $200 \mathrm{~km}$ in-stream dispersal) and in the African clawed frog (between 1 and 20 $\mathrm{km}$ overland dispersal). Values displayed represent 100 replicates of colonization simulations across the whole river network (a) and across the mainstreams (b) for the beaver and only across the whole network for the frog (c). 


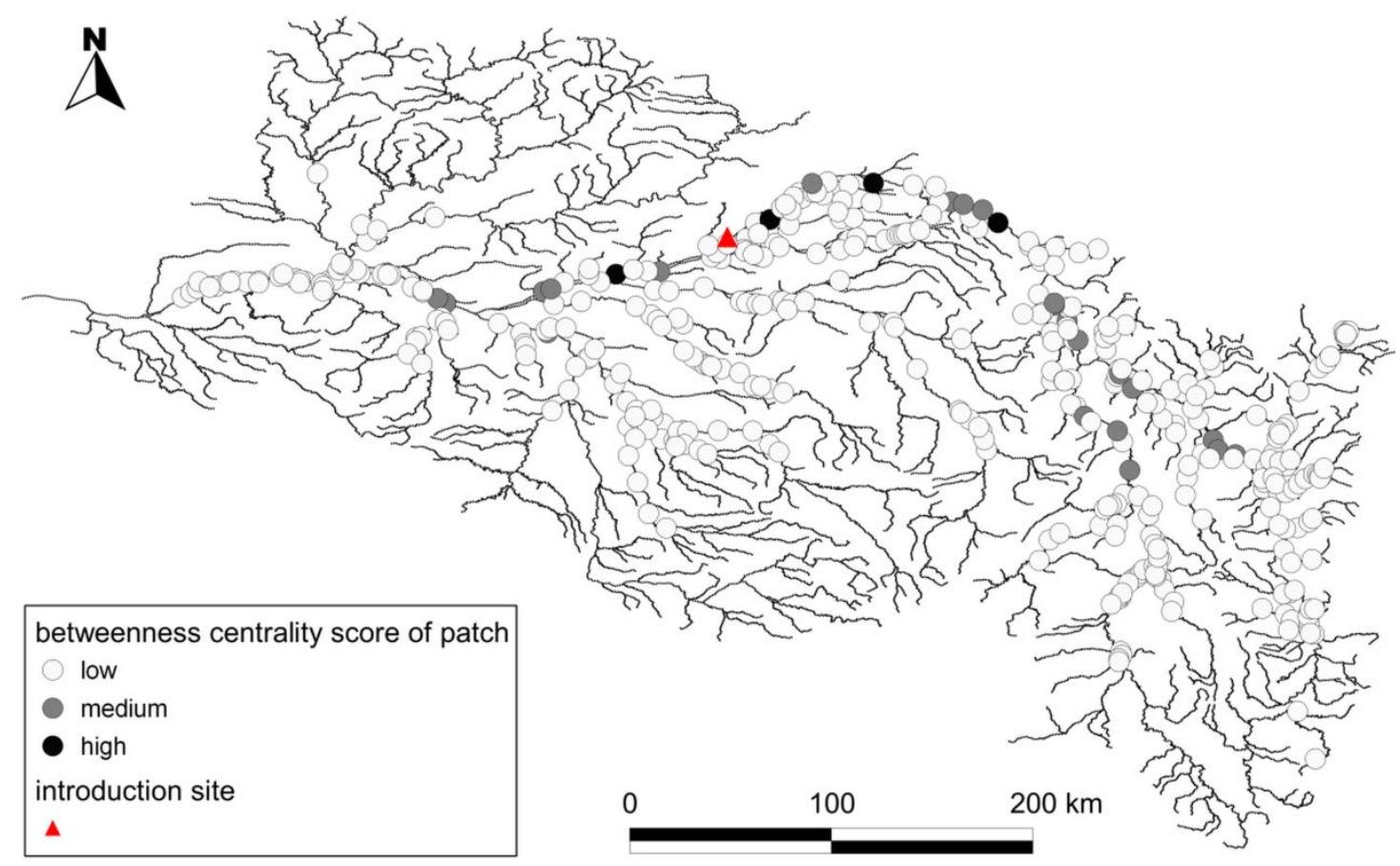

Fig. 3. Location of patches occupied by the Eurasian beaver $(n=399)$ according to their betweenness centrality scores. Scores correspond to a 80-km dispersal distance (low $=0-8$ 440 , medium $=8440-34733$, high $=34$ 733-79 617). 


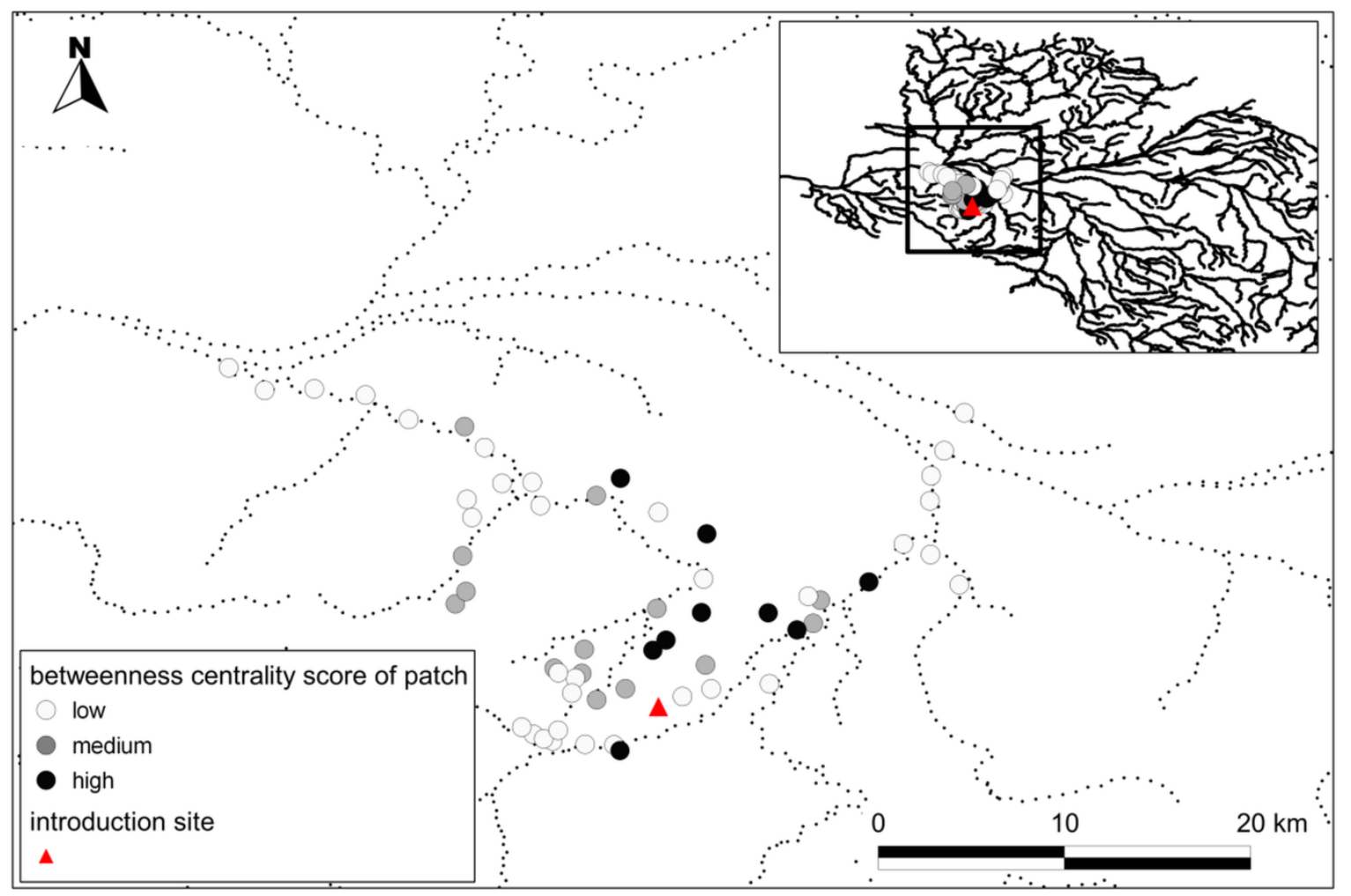

Fig. 4. Location of patches occupied by African clawed frog $(n=57)$ according to betweenness centrality scores. Scores correspond to 4-km dispersal distance (low $=0-63$, medium $=63-210$, high $=210-523$ ). 


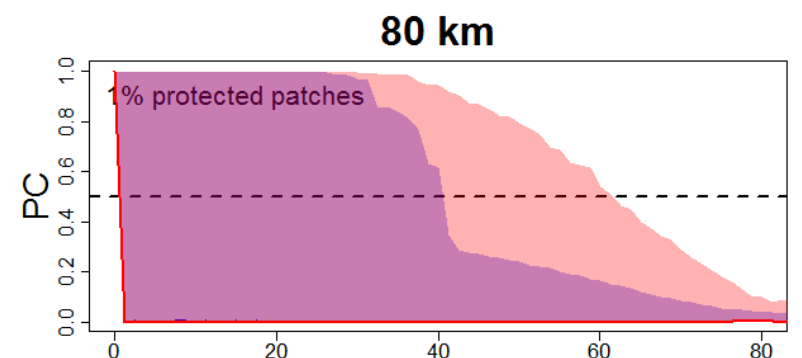

80 km

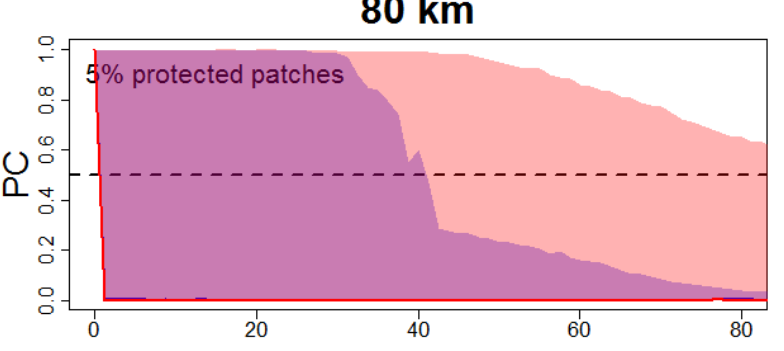

80 km

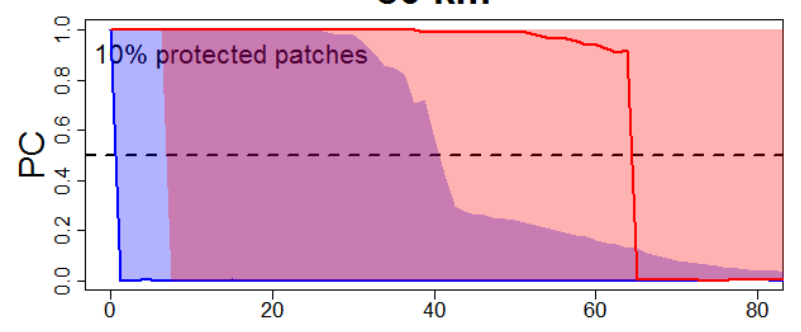

$120 \mathrm{~km}$

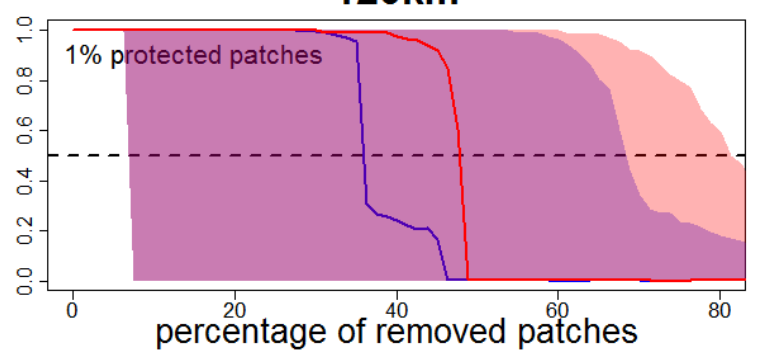

120 km

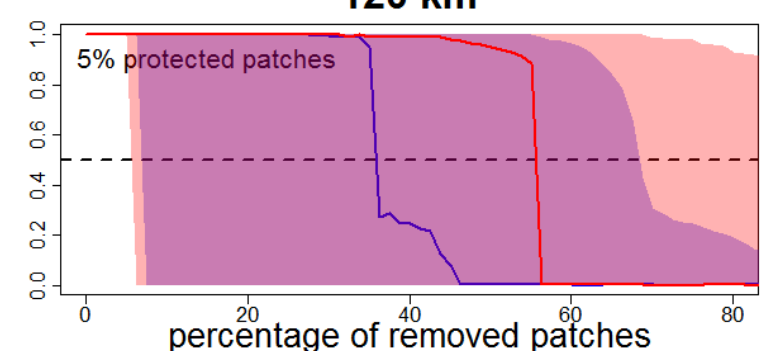

120 km

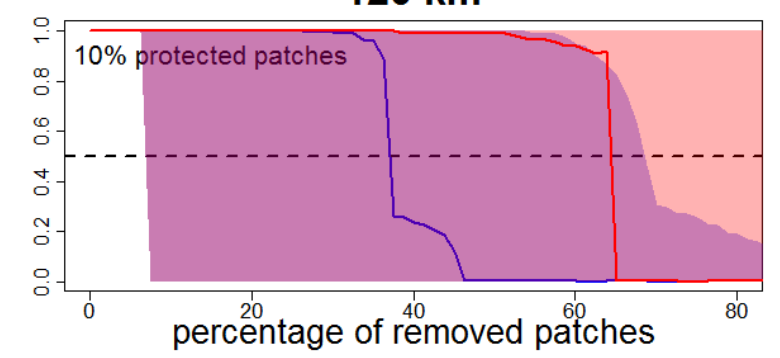

$160 \mathrm{~km}$

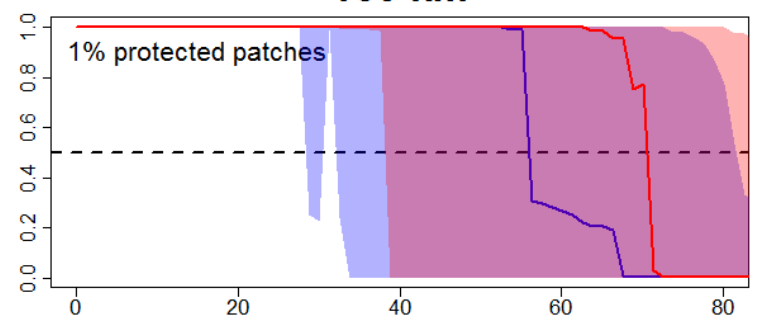

$160 \mathrm{~km}$

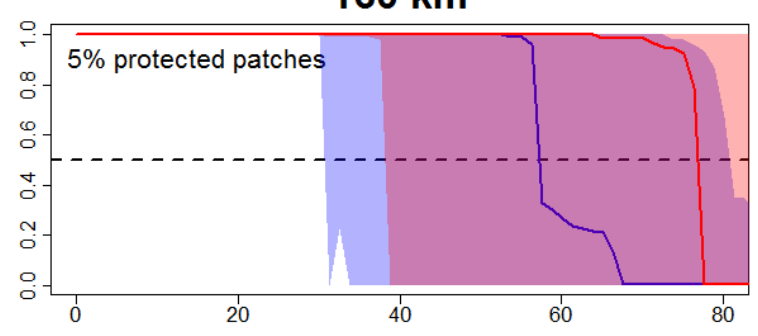

$160 \mathrm{~km}$

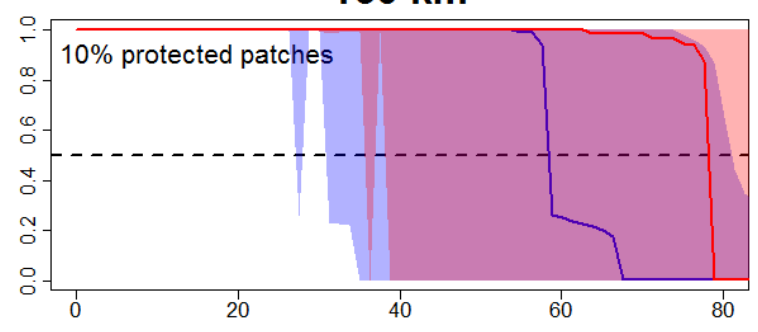

Fig. 5. Relative efficiency of protection strategies in the Eurasian beaver - Robustness of the network ( $\mathrm{n}=399$ patches) to fragmentation for 3 dispersal distances $(80,120,160 \mathrm{~km})$ and the percentage of protected patches $(1,5,10 \%) . P C$ as a function of removed patches for two management strategies of patches: random (blue) and targeted (red) protections. Lines represent the median value; areas represent the $95 \%$ and $5 \%$ quantiles of the distribution as network fragmentation was performed 1000 times. A purple area corresponds to an overlap between distributions of random (blue) and targeted (red) strategies. The dashed line corresponds to a value of $P C=0.5$. 

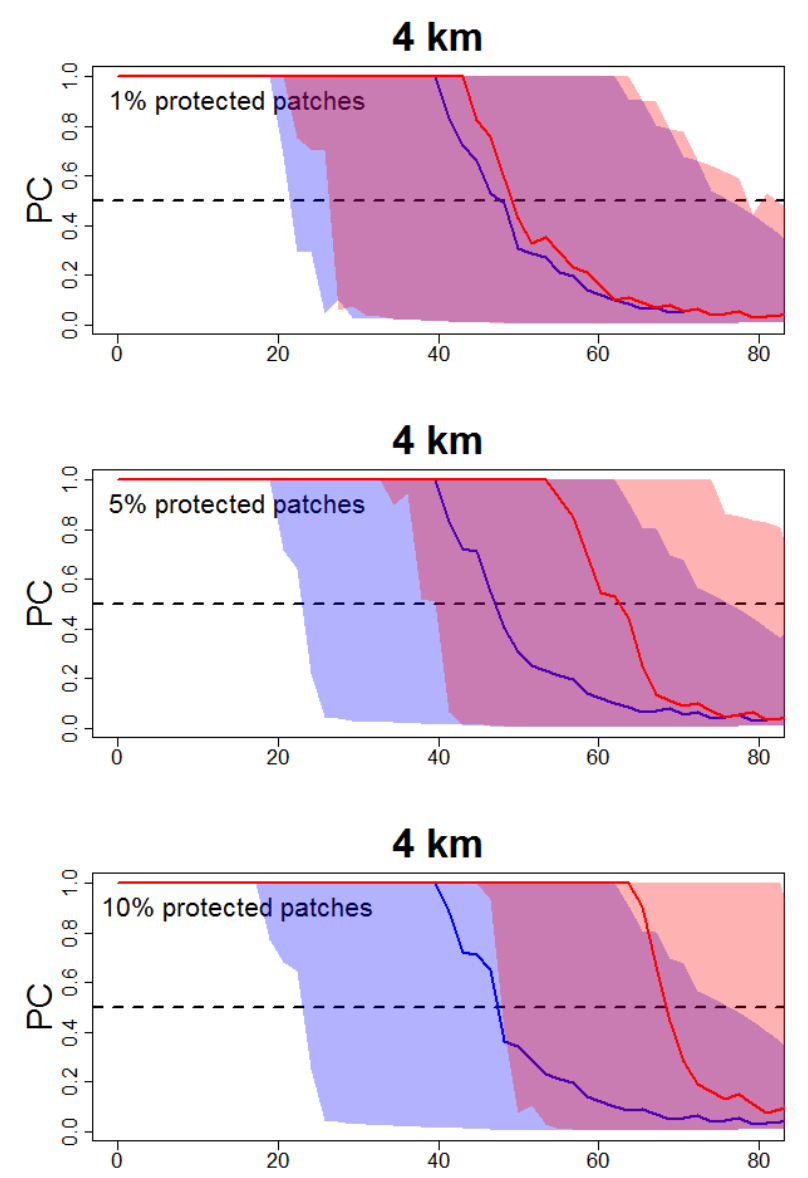

$6 \mathrm{~km}$

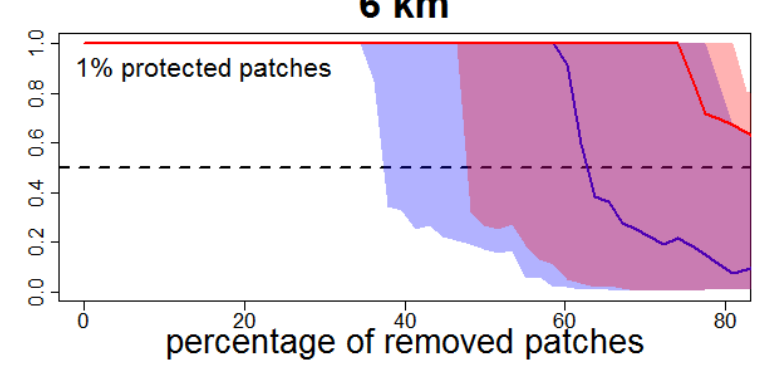

$6 \mathrm{~km}$

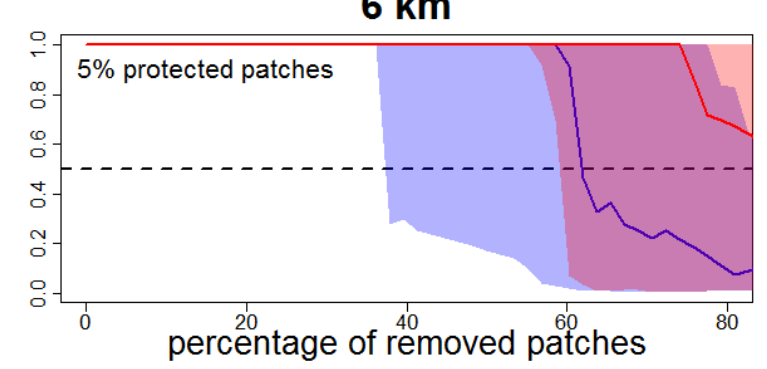

$6 \mathrm{~km}$

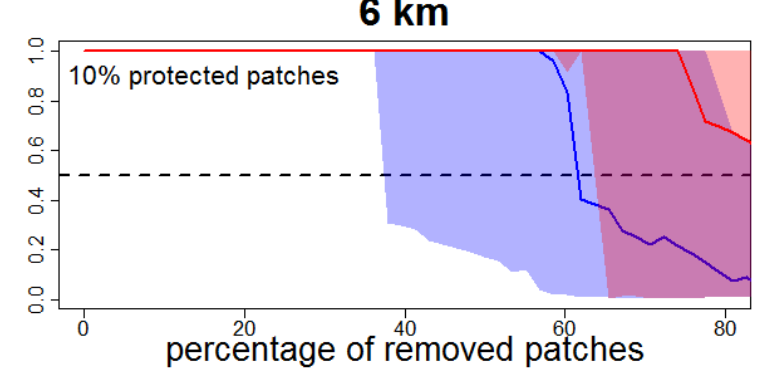

$8 \mathbf{~ k m}$
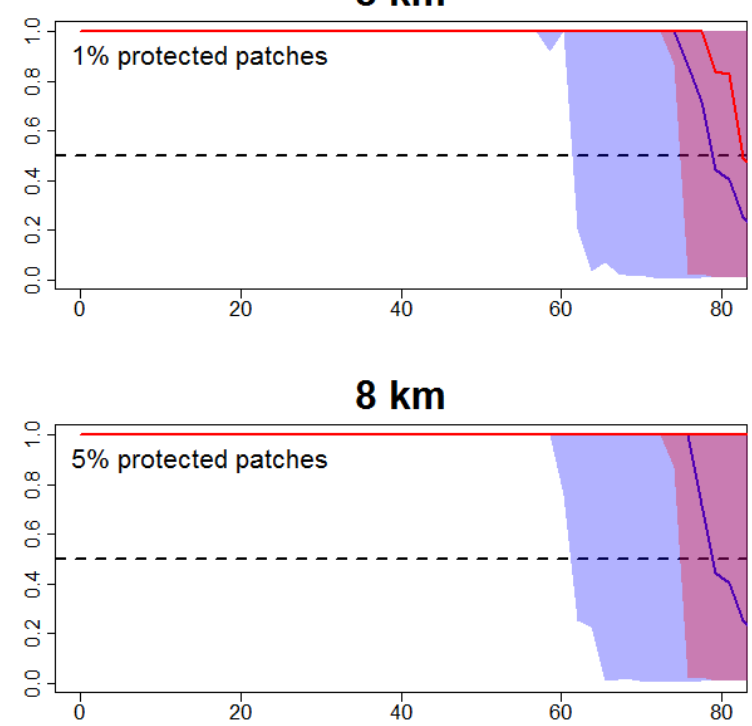

$8 \mathbf{~ k m}$

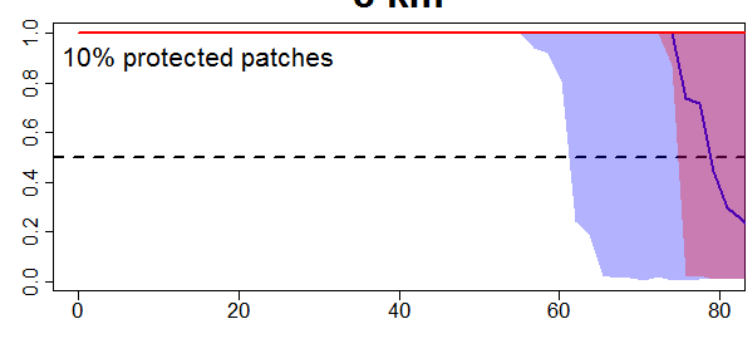

Fig. 6. Relative efficiency of protection strategies in the African clawed frog - Robustness of the network $(\mathrm{n}=57$ patches) to fragmentation according to dispersal distances $(4,5$ and $6 \mathrm{~km})$ and the rate of protected patches $(1,5$ and 10\%). $P C$ as a function of removed patches for two management strategies of patches: random (blue) and targeted (red) protections. Lines represent the median value; areas represent the $95 \%$ and $5 \%$ quantiles of the distribution as network fragmentation was performed 1000 times. A purple area corresponds to an overlap between distributions of random (blue) and targeted (red) strategies. The dashed line corresponds to a value of $P C=0.5$. 
$80 \mathrm{~km}$

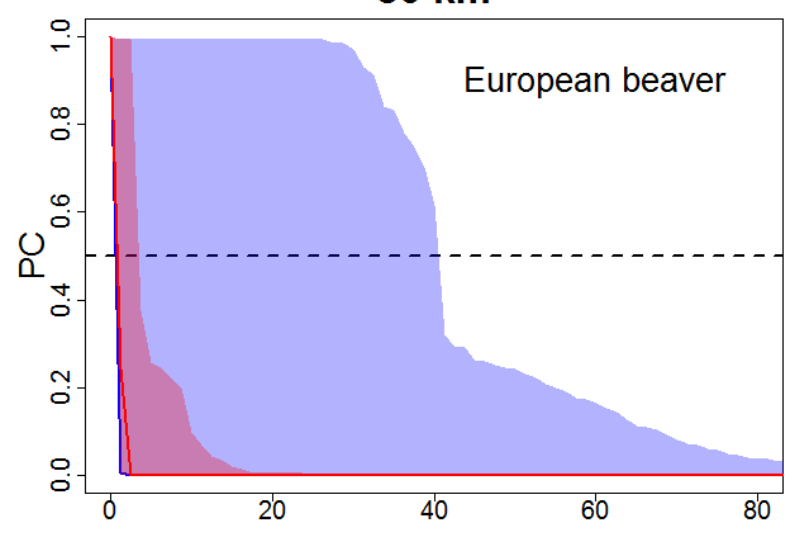

$4 \mathbf{~ k m}$

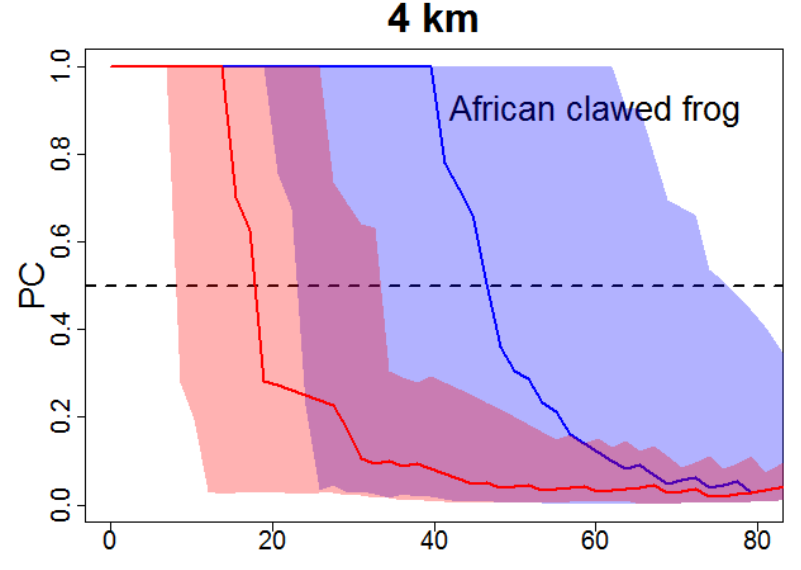

$120 \mathrm{~km}$

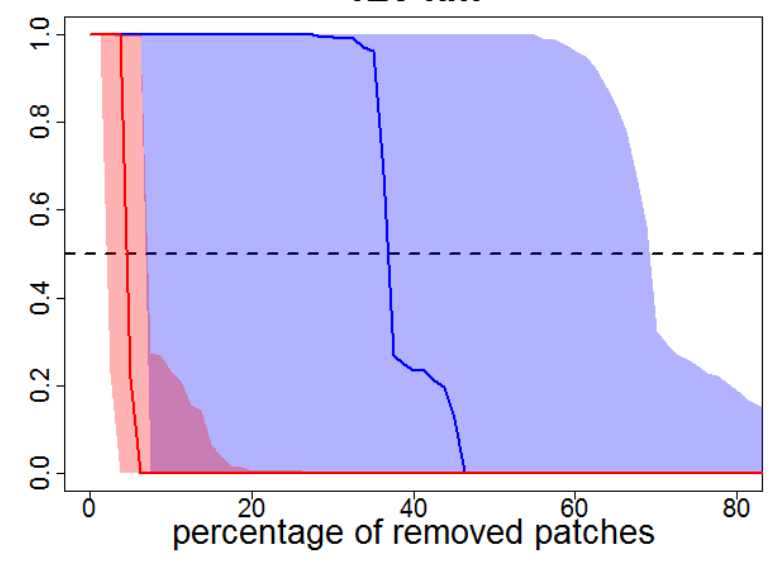

$6 \mathrm{~km}$

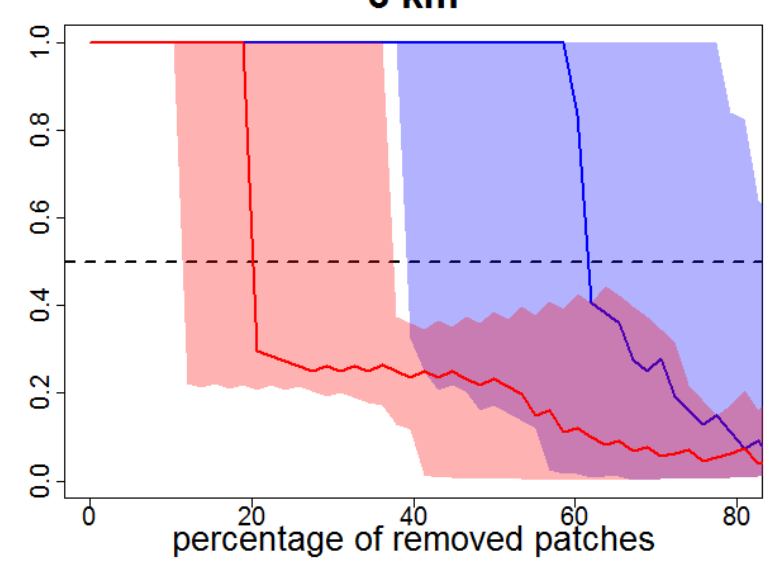

$160 \mathrm{~km}$
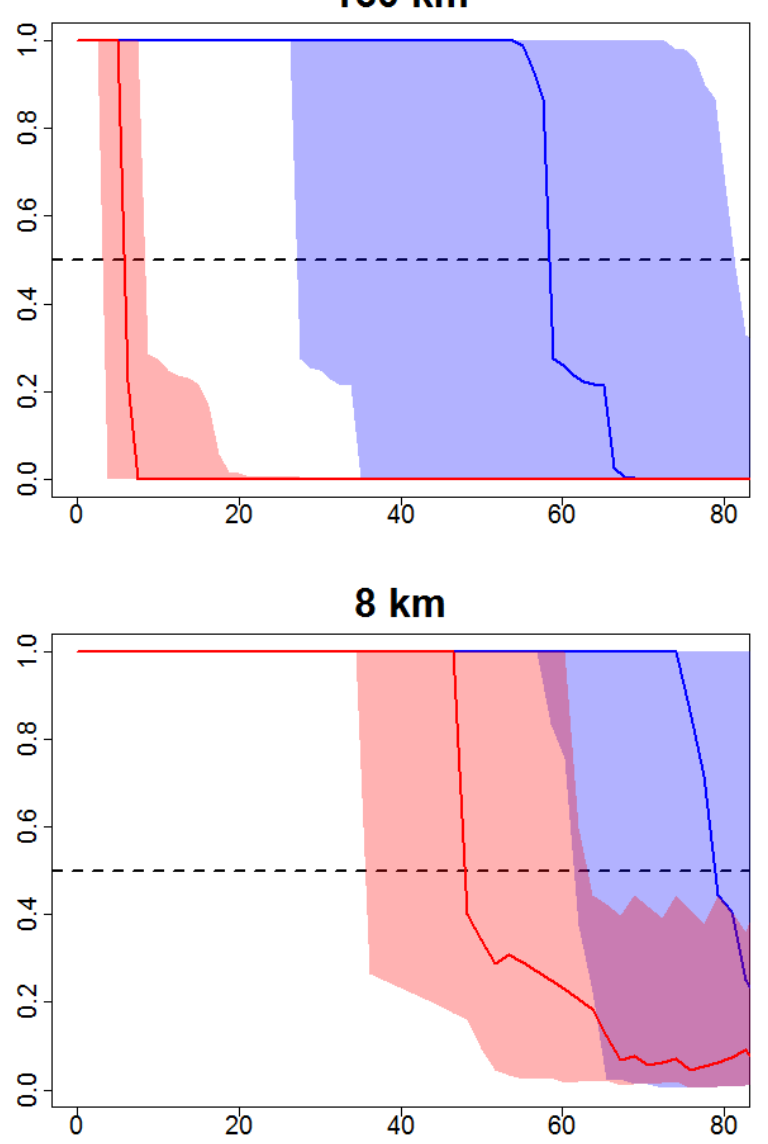

Fig. 7. Relative efficiency of control strategies in the Eurasian beaver and African clawed frog- Robustness of the network to fragmentation according to dispersal distances. $P C$ as a function of removed patches for two management strategies of patches: random (blue) and targeted (red) controls. Lines represent the median value; areas represent the 95\% and 5\% quantiles of the distribution as network fragmentation was performed 1000 times. A purple area corresponds to an overlap between distributions of random (blue) and targeted (red) strategies. The dashed line corresponds to a value of $P C=0.5$. 